\title{
Porcine Lactic Dehydrogenase in the Serum of Patients Treated by Extracorporeal Porcine Liver Perfusion
}

\author{
I. BERSOHN,* M.B., B.SC., F.C.PATH. ; M. C. KEW, $\dagger$ M.D., F.C.P.(S.A.)'; M. ROLLE, $\ddagger$ B.A. ; \\ C. J. MIENY,§ M.CH., F.R.C.S. ; J. A. MYBURGH,\| M.CH., F.R.C.s.
}

British Medical fournal, 1969, 2, 84-88

\begin{abstract}
Cummary : Porcine lactic dehydrogenase (L.D.H.) has $N$ been found in the serum of four patients in hepatic coma treated by extracorporeal porcine liver perfusion. A comparison between the porcine L.D.H. isoenzyme pattern in the patients' serum and that in porcine serum and liver extract indicates that the porcine L.D.H. is derived from the pig liver. This finding reflects damage to the pig liver cells sustained during porcine hepatectomy and subse-. quent perfusion. Possibly patients might develop immune reactions against porcine substances when these entered the circulation, especially if perfusion was repeated after an interval of some time.
\end{abstract}

\section{Introduction}

Porcine albumin and globulins have been found in the serum of patients in hepatic coma treated by extracorporeal porcine liver perfusion (Norman, Saravis, Brown, and McDermott, 1966 ; Norman, Hardison, and McDermott, 1967 ; Watts, Douglas, Dudley, Gurr, and Owen, 1967). This observation has been interpreted as evidence of the normal functioning of the pig liver, with synthesis occurring during the perfusion. The purpose of this communication is to report the detection of porcine lactic dehydrogenases in the serum of patients treated by extracorporeal pig liver perfusion. Evidence is presented that this observation reflects cell damage in the perfused pig liver rather than physiological function.

\section{Patients and Methods}

Four patients in hepatic coma have been studied. Liver failure was due to fulminating viral hepatitis in two iases, to alcoholic cirrhosis aggravated by a two-week alcoholic "binge" in one case, and to a massive bleed from oesophageal varices in the other. All the patients were jaundiced and had raised blood ammonia levels. Extracorporeal porcine liver perfusion was carried out according to the method described by Liem, Waltuch, and Eiseman (1964). The pig liver was exsanguinated and then rinsed free of porcine blood with iced Ringerlactate solution before being connected to the patient. Perfusion was carried out for periods ranging from three and a half to six hours. Blood was taken from the patients before beginning the perfusion and at intervals varying from 15 to 60 minutes throughout the procedure. Two of the patients died

- Superintendent, Clinical Pathology and Head of the Liver Function and Enzyme Units, South African Institute for Medical Research, Johannesburg.

t Physician, Department of Medicine, University of the Witwatersrand, Johannesburg.

¥ Research Assistant, South African Institute for Medical Research, Johannesburg.

S Senior Surgeon, Department of Surgery, University of the Witwatersrand, Johannesburg.

II Principal Surgeon, Department of Surgery, University of the Witwatersrand, Johannesburg. during or shortly after the perfusion. In the surviving patients blood was taken daily after completion of the perfusion.

Horizontal starch-gel electrophoresis was used to fractionate pig serum, an extract of fresh pig liver, and sera from the patients. Electrophoresis was performed in an ice-cooled Shandon tank. The gel buffer used was $0.076 \mathrm{M}$ tris (tri-(hydroxymethyl) methylamine) and $0.005 \mathrm{M}$ citric acid $p \mathrm{H} \mathrm{8.65}$, and the Bridge buffer was $0.3 \mathrm{M}$ boric acid and $0.05 \mathrm{M}$ sodium hydroxide $\mathrm{pH}$ 8. After a three-hour run $(7.5$ volt $/ \mathrm{cm}$. length and $5 \mathrm{~mA} / 2.5 \mathrm{~cm}$. width, the power pack on constant current) the gel was incubated at $37^{\circ} \mathrm{C}$. in the dark in a reaction mixture containing: sodium lactate, $2(p-$ iodophenyl)-3-( $p$-nitrophenyl)-5-phenyl tetrazolium chloride, $\mathrm{N}$-methyl phenazonium methosulphate, and beta-nicotinamide adenine dinucleotide in $0.06 \mathrm{M}$ potassium phosphate buffer $\mathrm{pH} 7.5$ for one hour. After incubation the gel was rinsed with $10 \%$ glacial acetic acid to stop the reaction, rinsed with Elgastat-prepared deionized water, placed in $80 \%$ glycerol, and photographed the following day.

\section{Results}

With starch-gel electrophoresis five isoenzymes of lactic dehydrogenase (L.D.H.) can be recognized in the serum of man and pig, L.D.H. 1 being the fastest-moving fraction. In porcine serum L.D.H. 1 is present in greatest concentration. Each porcine isoenzyme occupies a position slightly anodic to the corresponding human fraction (Fig. 1). Owing to this difference in mobility, L.D.H. from pig serum can be distinguished from human L.D.H. isoenzymes.

Pig liver extract contains only L.D.H. 1 to 4 isoenzymes, and L.D.H. 2 and 3 are present in the greatest concentration (Fig. 2). The pattern therefore differs from that in porcine serum.

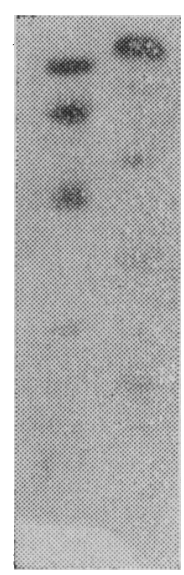

FIG. 1

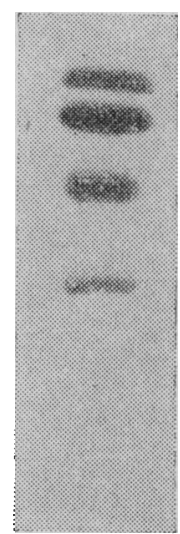

Fig. 2
FIG. 1.-Serum lactic dehydrogenase isoenzymes of the patient and the pig before perfusion. Top=Anode. Bottom=Cathode. Left= Patient's serum. Right = Pig's serum. FIG. 2.- Lactic dehydrogenase isoenzymes of pig liver extract. 
Porcine L.D.H. could be demonstrated in the serum of each of the four patients (Fig. 3). The isoenzymes appeared within a few minutes of the beginning of perfusion and increased progressively in concentration, reaching a maximum at the end of the procedure (Fig. 3). Porcine fractions 1 to 4 were present, L.D.H. 2 and 3 being in greatest concentration (Fig. 3). In the two surviving patients the porcine isoenzymes persisted in the human serum in decreasing concentrations for 48 to 72 hours.

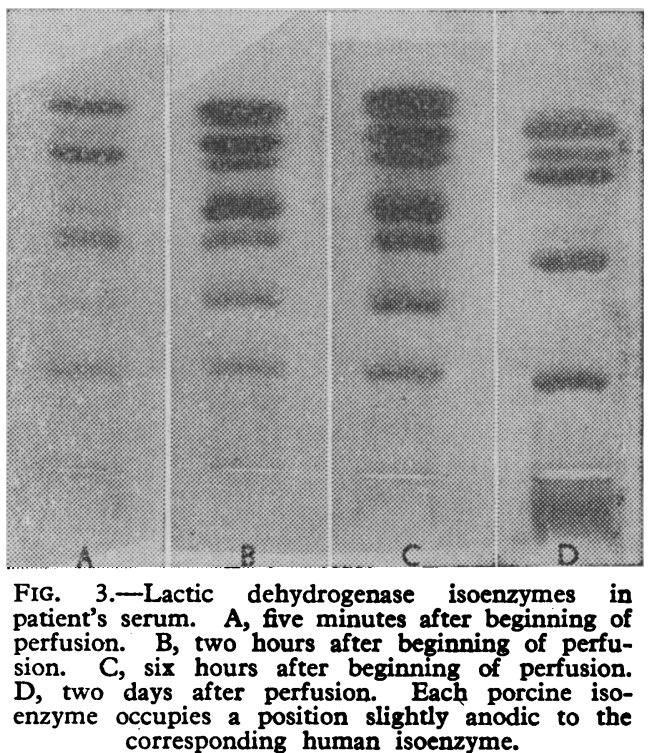

\section{Discussion}

The L.D.H. in human serum originates in several tissues, including the liver. In man all five fractions are found in the liver, but L.D.H. 5 is predominant (Vesell, 1961). The serum concentration of L.D.H. 5 in particular is greatly increased when liver cell damage occurs (Wieme and Van Maercke, 1961). In the pig, however, only L.D.H. 1 to 4 are found in the liver, though L.D.H. 5 is present in the serum. L.D.H. 2 and 3 are the predominant hepatic isoenzymes. The detection of porcine L.D.H. 1 to 4 in the serum of the patients during the perfusion and the fact that L.D.H. 2 and 3 were present in greatest concentration therefore indicates that the porcine isoenzymes originated from the liver cells and not merely from porcine plasma which had not been adequately removed from the liver. This conclusion is supported by the observation that the concentration of porcine L.D.H. increased progressively during the perfusion. It is apparent that some damage to the porcine liver cells had occurred and was responsible for the leakage of L.D.H. into the patient's serum. The process of porcine hepatectomy and subsequent flushing to remove traces of porcine blood is probably responsible for the initial injury, which would be ischaemic in origin. This initial damage is reflected by the early appearance of porcine L.D.H. in the patient's serum. The progressive increase in the concentration of the enzyme is probably due to damage incurred during the course of the perfusion, over and above the original injury. Other enzymes present in large quantities in pig liver cells will enter the patient's circulation for the same reasons.

Our observations re-emphasize the possibility of immune reactions developing against porcine substances entering the patient's circulation (Norman et al., 1966, 1967 ; British Medical fournal, 1967). So far no anaphylactic or other unfavourable immunological reactions have been reported in patients having repeated perfusions (Norman et al., 1966, 1967 ; van Wyk and Eiseman, 1966 ; Watts et al.; 1967). Nevertheless, these have been performed over relatively short periods of time (up to 18 days) and reactions may well develop when perfusions are repeated after longer intervals.

We wish to thank the Director and Deputy Director of the South African Institute for Medical Research, Professors J. H. S. Gear and J. F. Murray, for their interest in this study.

REFERENCES

British Medical fournal, 1967, 2, 332.

Liem, D. S., Waltuch, T. L., and Eiseman, B. (1964). Surgical Forum, 15, 90.

Norman, J. C., Hardison, W. G., and McDermott, W. V. (1967). Bulletin of the New York Academy of Medicine, 43, 967.

Norman, J. C., Saravis, C. A., Brown, M. E., and McDermott, W. V., jun. (1966). Surgery, 60, 179.

van Wyk, J., and Eiseman, B. (1966). South African Medical fournal, 40,

Vesell, E. S. (1961). Annals of the New York Academy of Sciences, 94, 877.

Watts, J. McK., Douglas, M. C., Dudley, H. A. F., Gurr, F. W., and Owen, J. A. (1967). British Medical Yournal, 2, 341.

Wieme, R. J., and Van Maercke, Y. (1961). Annals of the New York Academy of Sciences, 94, 898.

\title{
Assessment of Size of Small Volume Foeto-maternal Bleeds. A New Method of Quantification of the Kleihauer Technique
}

\author{
PETER JONES,* M.D., D.C.H.
}

Cummary : The risk of $\mathbf{R h}$-isoimmunization is probably related to the volume of foeto-maternal bleeding. With the Kleihauer technique foetal cells may be detected in maternal blood, but estimation of the size of foetal bleed the cells represent is at present difficult and open to serious error.

A new method of quantifying the technique by using a standard volume of maternal blood, and a simple machine for the preparation of comparable blood films, is described. The new method eliminates many of the errors of previous techniques, and should be capable of automation for large-scale screening programmes.

\section{Introduction}

Small foeto-maternal bleeds occur in nearly all pregnancies, but only rarely is the bleeding sufficient to cause severe anaemia of the newborn. "Small bleeds" represent a dilution factor of 1 foetal cell to 10,000-100,000 maternal red cells, and as little as $0.25 \mathrm{ml} .(1: 20,000)$ of rhesus-positive cells (Woodrow et al., 1965), or possibly less (Zipursky, 1966), may stimulate antibody formation in a rhesus-negative individual. Because the risk of rhesus isoimmunization is related to the size of foeto-maternal

\footnotetext{
- Department of Child Health, Royal Victoria Infirmary, Newcastle upon
} Tyne. 